\title{
APROXIMACIONES AL TRABAJO ARCHIVÍSTICO DE LA IGLESIA
}

La Orden de san Agustín en el archivo del arzobispado de Lima

\begin{tabular}{c}
\hline Aida Luz Mendoza Navarro* \\
Universidad Católica Sedes Sapientiae
\end{tabular}

Fecha de recepción: septiembre de 2012 Fecha de aceptación: octubre de 2012

RESUMEN: En este documento se aborda brevemente la historia de los archivos de la Iglesia. La autora destaca su importancia porque en los archivos se puede encontrar diversa información para la reconstrucción de los hechos que marcaron su historia, precisando que estos no estuvieron exentos de haber sufrido la pérdida de sus documentos, aunque los diferentes Papas tomaron algunas medidas que contribuyeron a la protección de sus archivos. Demuestra de esta manera la sensibilidad de los Papas, cuyas acciones en favor de los archivos permitieron mejoras en la custodia y conservación de la memoria de la posteridad consignada por los escritos que se fueron acumulando en los archivos eclesiásticos, a la vez que comenta cómo se

* Aída Luz Mendoza Navarro fue Jefa del Archivo General de la Nación entre 19922001. Es abogada y magíster en Gestión de Políticas Públicas, coordinadora-docente de la Carrera Profesional de Archivística y Gestión Documental en la Universidad Católica Sedes Sapientiae. Ha participado en calidad de ponente y/o asistente en eventos nacionales e internacionales.

Participó como Miembro del CLAID team (Caribbean and Latin American Inter PARES Dissemination), con sede en The University of British Columbia, VancouverCanadá. Miembro del Foro Iberoamericano de Evaluación de Documentos (FIED). Autora de libros y 79 artículos publicados en ediciones especializadas nacionales y extranjeras. 
preocuparon por cada una de las actividades que se realizan los archivos, una de ellas y quizá la más importante es el servicio de los documentos. Palabras Clave: archivo, Iglesia Católica, Orden de san Agustín,

AвSTRaCT: This document briefly deals with the history of the Church archives. The author emphasizes their importance since we can find information for the reconstruction of the events that marked the Church's history. Even though the files were well kept by different Popes who took some measures to protect them, some documents were lost. Thus, we demonstrate the Popes' sensitivity and actions to make improvements in the custody and preservation of the memory accumulated in the ecclesiastic archives, and at the same time their concern about the most important activity, the service of documents.

Kerwords: file, Catholic Church, Order of saint Augustine

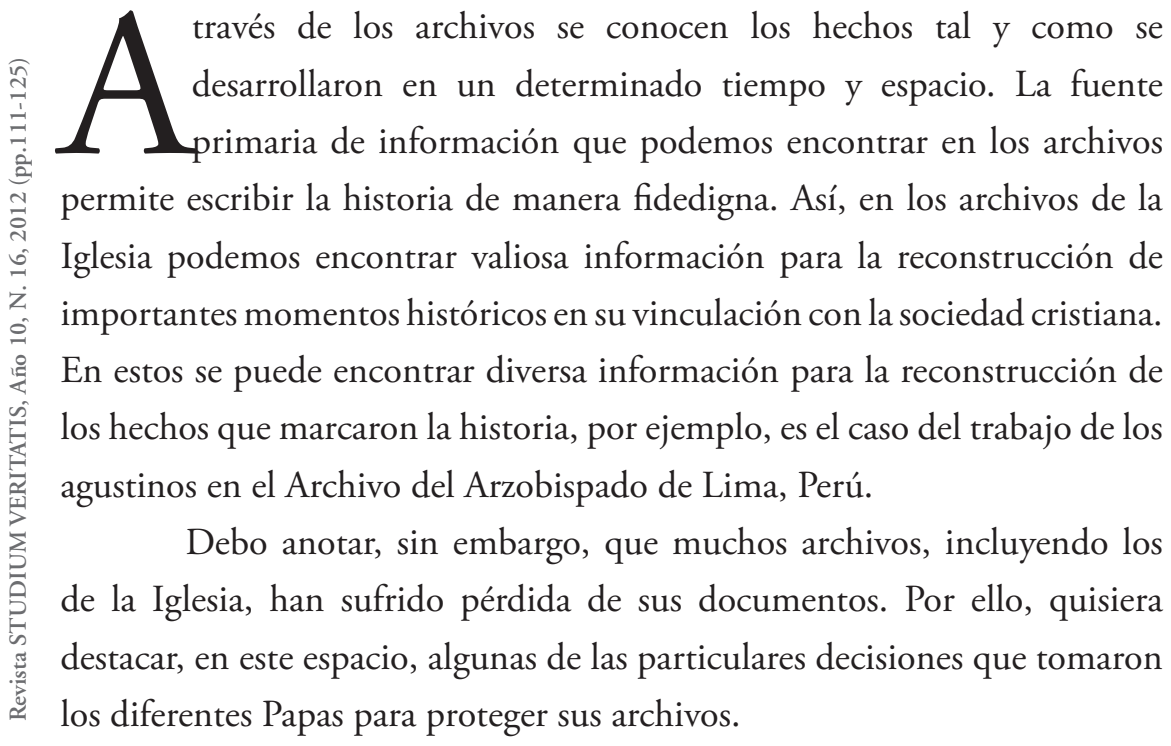




\section{LOS PAPAS ARCHIVEROS}

Durante el Pontificado de Sixto V (siglo xvi) y la reorganización de la Curia Romana se establecieron dos disposiciones:

a) Cómo, en las congregaciones, nacen por vía administrativa los documentos y

b) cómo deben pasar a los respectivos archivos. (Cf. Aguilera y Garibay 2010: 34 )

Sin mencionarlo, el Papa logró precisar el ciclo vital de los documentos de archivo. Este se planteó desde su producción, mientras se encuentran en gestión, y por tanto se ubican en un archivo administrativo de la Iglesia, hasta llegar al archivo histórico en la última fase de su ciclo vital.

Por otro lado, los Papas del siglo XviI tuvieron una preocupación especial por los archivos. Así lo señalan Aguilera y Garibay cuando destacan "su preocuparon por la cuestión archivística», y precisan un ejemplo con la construcción del archivo Notarial de Roma, o mediante alguna disposición, como cuando el Papa Clemente XI publicó dos bandos contra la destrucción, entre otros bienes, de los libros manuscritos y toda clase de documentos (Cf. Aguilera y Garibay 2010: 35).

Resulta muy importante la norma expedida por el Papa Clemente XI debido a que los archivos en todas las épocas han sido afectados por siniestros o actos contrarios a las leyes, provocando la destrucción de los documentos más valiosos de la Iglesia (Cf. Aguilera y Garibay 2010: 35). Además, nótese que se refiere a toda clase de documentos, con lo cual el alcance del bando es mucho más amplio, en tanto implica la protección 
de todo tipo de documentos en los que se incluyen los archivos y los documentos bibliográficos.

Es interesante recordar al llamado «Papa archivero», Benedicto XIII, quien como Obispo realizó una serie de acciones (Cf. Aguilera y Garibay 2010: 36):

-Organizó el archivo diocesano, recogiendo los documentos dispersos y restaurando los papeles que así lo ameritaban.

-Instituyó los archivos en cada parroquia,

-Dispuso que, al menos, hubiera un armario digno y seguro para conservar los documentos.

-Publicó dos escritos: un método para preparar los inventarios de los bienes eclesiásticos y un formulario para redactar las actas en libros parroquiales.

-Por medio del Sínodo de Benevento (1693) emitió normas para los archivos eclesiásticos de su jurisdicción.

-Celebró el Sínodo romano (1725), en el dispuso que en el espacio de un año se realizaran copias del inventario de las escrituras de las diócesis, estableciendo que una copia debía ir al archivo episcopal. Encargó a Pietro Donnino levantar el inventario del Archivo Secreto Vaticano.

-Su preocupación llegó hasta la publicación de la Constitución Apostólica Máxima Vigilatia (1727) que reflejaba nítidamente el pensamiento de la Iglesia romana en materia archivística y la preocupación por establecer normas para proteger el patrimonio cultural. 
Este documento muestra la sensibilidad del Papa por los archivos. Iniciaba con un exordio en el que se planeaba la tradición de la Iglesia en la custodia y conservación de la memoria de la posteridad consignada por escritos; se hablaba de armarios, escritorios, almacenes, arcas y archivos que guardaban escritos, diplomas, códices y documentos oficiales para preservarlos de los tiempos y los hombres, y así estar en condiciones de transmitirlos a la posteridad (Cf. Aguiler y Garibay 2010: 36). La preservación a través del tiempo y la necesidad de contar con el mobiliario adecuado para conservar los documentos de archivos se explica porque la acción del tiempo sobre los documentos en soporte de papel es una de las causas de su progresivo deterioro; de allí la necesidad de protegerlos contando con los muebles más adecuados para conservarlos, entre otras medidas dirigidas al mismo fin.

Por otro lado, debo destacar que cuando se refiere «preservarlos de los tiempos y de los hombres» está haciendo una advertencia sumamente importante. La acción del hombre, en muchos casos, ha ocasionado las más grandes pérdidas de documentos, sea por negligencia en la custodia, por la manipulación inadecuada o por hechos muchos más graves, como los hurtos que son acciones delincuenciales contra los archivos. Además diversos siniestros, en todas las épocas, han ocasionado la desaparición de grandes cantidades de documentos.

Según refieren los autores, tantas veces citados, el motivo de la disposición papal fue porque había el rumor que en muchas diócesis se descuidaban los archivos con la respectiva pérdida de documentos. Se encomendaba también a las autoridades eclesiásticas disponer de un lugar para sede del archivo en la diócesis y una inspección a los seis meses después de promulgada la Constitución para verificar el estado del archivo. Se señalan en detalle que los lugares debían ser seguros, convenientes y secos. Se mandaba la elaboración de un inventario y un catálogo de los documentos 
que deberían ser validados con la firma de la autoridad, y la necesidad de su actualización cada año en el mes de enero para registrar las escrituras precedentes (Cf. Aguilera y Garibay 2010: 36).

Como podemos apreciar se cuidaron muchos aspectos archivísticos, como locales adecuados para el archivo, la seguridad y las condiciones ambientales idóneas para la conservación de los documentos (se indica, por ejemplo, que los lugares deberían ser 'secos'). Sabemos que las óptimas condiciones climáticas son determinantes para la conservación de los documentos.

Otros aspectos tratados fueron la seguridad y la responsabilidad:

- Seguridad: disponía la existencia de dos llaves con dos cerraduras distintas, de modo que ninguna de las dos por si sola abriera el archivo, determinándose quien debía tener la llave. En el caso de archivo diocesano el código dispone un custodio nombrado por el obispo. La norma paso después al Código de Derecho Canónico de 1917.

- Responsabilidad: todo archivo debía ser cuidado por una persona ad hoc nombrada por la institución según las normas y tradiciones canónicas (Cf. Aguilera y Garibay 2010: 36).

Es notorio que el Papa se preocupó de cada una de las actividades que realizan los archivos, una de ellas y quizá la más importante es el servicio de los documentos. Al respecto, también dictó normas para su préstamo. Anexa a la Constitución el Papa, redactó una instrucción detallada de los documentos que deberían ser conservados en el archivo considerando dos secciones: 
a) Documentos que todo archivo debe guardar: actas de fundaciones de obispados, monasterios, etc., privilegios, concesiones, testamentos donaciones, etc.

b) Para cada organismo: diócesis (decretos, visitas, escrituras referentes a la Inquisición, licencias de párrocos, dimisiones, testimoniales, etc.), parroquias (libros sacramentales, libros de estado de ánimas, libros de gobierno, etc.), órdenes y congregaciones (documentos de aprobación pontifica, ejemplares de las reglas, registros de ingresos y egresos de novicios y religiosos, etc.) (Cf. Aguilera y Garibay 2010: 37).

El Papa León XIII abrió el archivo Secreto al mundo científico y dio el Reglamento (1902) para la custodia y uso de los archivos y bibliotecas eclesiásticas. El objetivo era asegurar el buen orden, la conservación e integridad de los documentos y proveer el uso conveniente de ellos:

- Se recomendaba organizarlos mediante una adecuada clasificación con las signaturas o titularios correspondientes y darles un signo de pertenencia por medio del sello.

- En cuanto a la organización documental, se advertía que, en caso de que algún archivo hubiere estado ordenado anteriormente, se respetara aquel orden acatando el principio de procedencia.

- Control de los documentos por medio de inventarios y los catálogos.

- Medidas para custodiar y preservar los documentos de los peligros del fuego, del agua de los hombres y de todos los agentes y situaciones adversas. (Cf. Aguilera y Garibay 2010: 38) 
Como constatamos, todas las funciones archivísticas fueron precisadas. Una de ellas es la clasificación de los documentos y sus respectivas signaturas. No se omitieron elementos fundamentales del trabajo archivístico, como son el principio de procedencia y orden original. Asimismo, encontramos que la descripción archivística está presente en la disposición de preparación de inventarios y catálogos. Estos instrumentos descriptivos a la vez de facilitar la localización de los documentos permiten su debido control. De allí el valioso aporte de Laura Gutiérrez en la obra de nuestra atención.

La valoración de documentos, cuyo objetivo es determinar los valores primarios y secundarios, con la finalidad de conservar los documentos útiles para el usuario inmediato en las primeras fases de su ciclo vital y para los investigadores en su última fase, es puesta de relieve en el siguiente pronunciamiento del Papa Juan XXIII:

Lo estrecho de los locales y el continuo crecimiento de la documentación han hecho surgir en nuestros archivos el problema de la eliminación o la depuración de aquellos escritos, que puedan retenerse no más útiles. Pero la elección de éstos es una operación delicada y no fácil por el peligro de destruir papeles que más tarde podrían ser importantes. La eliminación sea llevada por tanto, después de una madura reflexión y jamás sea decidida por una sola persona. (EAE, 263-267; en Aguilera y Garibay 2010: 40)

En la segunda mitad del siglo xx la producción de documentos comenzó a preocupar a todo tipo de organizaciones y la iglesia no fue la excepción. No es posible conservar todo el volumen documental que 
se genera; en consecuencia, hay que tomar decisiones para eliminar los documentos innecesarios y conservar solamente aquellos documentos que mantienen su vigencia y los que ameritan ser calificados como de valor histórico, los cuales serán custodiados en un archivo histórico por ser de valor permanente. Sin embargo, tal como se desprende de lo manifestado por el Papa Juan XXIII, reconoce que se trata de una tarea además de técnica y especializada, muy comprometida, por lo que se aconseja que más de una persona tome la decisión, desde el momento que una vez destruidos los documentos, su recuperación no es posible. Un comité, en el que concurran los profesionales que conocen del tema y que tengan la representatividad de la organización respectiva, en el que no puede faltar el archivero, es lo más aconsejable. En muchos países existen normas procedimentales para la conformación y actuación de los comités, que para el caso de los documentos públicos es de obligatorio cumplimiento y referencial para los archivos privados.

Tal como lo refieren Aguilera y Garibay, el Papa Juan XXIII, en su Instrucción promulgada en 1960, con motivo de la constitución de la Pontifica Comisión para las Archivos Eclesiásticos de Italia, señaló que los registros constituían la obra de la Iglesia y eran de utilidad para la acción pastoral. Por tanto, debían ser cuidadosamente organizados siguiendo las técnicas archivísticas más actualizadas (EAE: 263-267; en Aguilera y Garibay 2010: 39). Sin duda, los documentos de los archivos, tanto para la iglesia como para cualquier organización, son fuente de información para el cumplimiento de sus objetivos, para el caso que nos ocupa, la evangelización.

En el mismo sentido, la Función Pastoral de los Archivos Eclesiásticos destaca la importancia de los archivos de trámite o corrientes en la vida de la comunidad eclesial porque estos archivos en el futuro se convertirán en históricos (Cf. Aguilera y Garibay 2010: 41). En mi opinión, 
esta advertencia es fundamental para garantizar que aquellos documentos que califican como de valor permanente lleguen a los archivos históricos. Erróneamente se piensa que únicamente los documentos históricos tienen valor como patrimonio cultural, porque esos documentos en la primera fase de su ciclo vital fueron administrativos; si en ese momento no se les brinda las condiciones indispensables para su conservación, no habrá archivos históricos.

Por esa razón, en los cánones 486 a 491 del Código de Derecho Canónico (1983), promulgado por el Papa Juan Pablo II, se establecen las disposiciones para la atención de los archivos. El canon $486 \$ 1$ señala que deben custodiarse con la mayor diligencia todos los documentos que se refieran a las diócesis o a las parroquias. Seguidamente en el numeral $\$ 2$ se establece que debe haber un lugar seguro en el que se conserven con orden manifiesto, y diligentemente guardados los documentos y escrituras correspondientes a los asuntos diocesanos, tanto espirituales como temporales. Entiéndase que el orden manifiesto significa la aplicación de las funciones archivísticas de organización y descripción. El siguiente numeral $₫ 3$ indica la obligación de mantener «un inventario o índice de los documentos que se guardan en el archivo, con un breve resumen del contenido de cada escritura».

La seguridad, el servicio y la salida de documentos están estipulados en los cánones 487 y 488. En el $487 \$ 1$ se establece que el archivo debe estar cerrado, y solamente el Obispo y el canciller deben tener la llave; a nadie se permite entrar en él sin permiso del Obispo, o del Moderador de la curia junto con el canciller. En lo que se refiere al servicio, el $\$ 2$ legisla sobre el derecho de los interesados a recibir personalmente, o por medio de un procurador, copia auténtica, escrita o fotocopiada, de aquellos documentos que siendo públicos por su naturaleza se refieran a su estado personal. La 
salida sin autorización de los documentos de la Iglesia queda normada en el canon 488, en el que se prohíbe retirar documentos del archivo si no es por poco tiempo y con el consentimiento del Obispo, o del Moderador de la curia junto con el canciller.

Respecto del archivo secreto y la valoración queda explicado en el canon 489. En el $\$ 1$ se señala que debe haber en la curia diocesana un archivo secreto, o al menos un armario o una caja dentro del archivo general, totalmente cerrada con llave y que no pueda moverse del sitio. En este se debe conservar con suma cautela los documentos que han de ser custodiados bajo secreto. La función de valoración está normada en el numeral $\$ 2$ del mismo canon. Se indica la destrucción de los documentos de aquellas causas criminales en materia de costumbres, cuyos reos hayan fallecido ya, o que han sido resueltas con sentencia condenatoria diez años antes, debiendo conservarse un breve resumen del hecho junto con el texto de la sentencia definitiva. Esta práctica se debe realizar cada año.

En los cánones 490 y 491 se dan las disposiciones para el acceso a los archivos, y la conservación de las actas y documentos contenidos en los archivos de las iglesias catedralicias, de las colegiatas, de las parroquias y de las demás iglesias de su territorio. Asimismo, se pide hacer inventarios o índices en doble ejemplar, uno de los cuales se guardará en el archivo propio, y el otro en el archivo diocesano. Igualmente, se expone sobre la necesidad de contar con un archivo histórico, y que en él se guarden con cuidado y se ordenen de modo sistemático los documentos que tengan valor histórico.

Las disposiciones papales que se fueron emitiendo en el tiempo fueron recogidas por el Código de Derecho Canónico de 1917 y el de 1983. En esa medida, la Iglesia cuenta con la normativa suficiente para proteger los documentos de sus archivos y brindar un servicio óptimo a sus usuarios. 


\section{EL TRABAJO ARCHIVÍSTICO}

A propósito del trabajo de los agustinos podemos exponer puntualmente la naturaleza e importancia del trabajo archivístico, además de la preservación de la memoria de la Iglesia en la investigación. Para ello es imprescindible referirse al trabajo de Laura Gutiérrez y Javier Campos y Fernández. Los investigadores han publicado recientemente La Orden de san Agustín en el Archivo del Arzobispado de Lima (Instituto Escurialense de Investigaciones Históricas y Artísticas, San Lorenzo del Escorial, 2012), en el que presentan un relato histórico breve, pero rico en información que invita a seguir descubriendo los hechos que registra la historia de la Orden religiosa en el Perú.

La exquisita invitación que se ofrece, muy bien atendida, con el Inventario trabajado por la archivera y especialista en archivos eclesiásticos, Laura Gutiérrez, permitirá a los investigadores consultar las series documentales o documentos de su interés para continuar construyendo la historia de los agustinos. Siendo el inventario el instrumento descriptivo más importante en un archivo, el que forma parte del título en comentario, tiene la particularidad de contener información suficiente para orientar la búsqueda del investigador. Se trata de un inventario esquemático que registra suficiente información para que el investigador pueda ubicar los documentos que requiere según el tema específico, sobre los agustinos, que desea investigar.

\section{El documento de archivo}

Como señalan Aguilera y Garibay, el historiador realiza su trabajo sobre diversos materiales; el más importante es el documento de archivo (Cf. Aguilera y Garibay 2010: 79). Es en los documentos inéditos, aun no 
consultados, donde podrá aprovechar mejor el documento, y constituye un privilegio del historiador porque le abre un nuevo panorama (Cf. Aguilera y Garibay 2010: 80). Los documentos de los archivos son indiscutibles fuentes de valiosa información para todo historiador. Los archivos no se forman de una reunión casual o arbitraria de documentos de una persona natural o jurídica. Los documentos crecen espontáneamente como resultado de las funciones y actividades de las instituciones, en este caso de la Iglesia.

El acervo documentario se da según el ritmo de desarrollo de la institución a la que pertenece y los documentos reflejan la estructura y razón de ser de esa institución. El material que consulta el historiador en un archivo muestra fielmente lo que aconteció, lo que surgió naturalmente como consecuencia de una acción determinada según la competencia y facultades del funcionario emisor del documento.

\section{Función del archivero}

En ese contexto, la función de archivero es darle el tratamiento técnico que los documentos requieren para ponerlo al servicio de los usuarios y de los investigadores. Ese tratamiento técnico demanda la aplicación de las funciones archivísticas de organización, descripción y conservación de los documentos en los archivos históricos y agregamos la valoración cuando se trata de un archivo administrativo, en tanto se deberá evaluar cuales son los documentos que se conservarán permanentemente por su valor histórico y se eliminarán aquellos que resulten innecesarios

Finalmente, permítanme referirme al mensaje del Pontificado de Paulo VI (1963-1979), alocución del 26 de setiembre de 1963, que dirigió en el V Congreso de la Asociación de Archiveros Eclesiásticos. Entre otras cosas escribió: 
Su Santidad está, además, muy contento de saber que personas competentes y apasionadas aman el archivo, es decir, la custodia del documento y el aprovechamiento que el documento puede dar. [...] Está convencido de que es necesaria la cultura histórica y que parte del genio, de la índole y de la necesidad, de las misma vida apostólica, la cual posee una tradición, es coherente, y desempeña en los siglos un diseño, y bien se puede decir, un ministerio. Es Cristo que opera en el tiempo y que escribe, el mismo, su historia, de tal modo que en nuestros pedazos de papeles hay ecos y vestigios de este paso de la Iglesia, es más del paso del Señor Jesús en el mundo.

Así es que entonces, el tener culto de estos papeles, de estos documentos, de los archivos, quiere decir, por reflejo, tener el culto de Cristo, tener el sentido de la Iglesia, dar a nosotros mismos, dar a quien vendrá la historia del paso de esta frase del transitus Domini en el mundo. (EAE, 277-279; en Aguilera y Garibay 2010: 40) ${ }^{1}$

En conclusión, el trabajo archivístico preserva la memoria de la historia y aporta a la investigación. El acervo documentario es el resultado del desarrollo de la institución a la que pertenece. Asimismo, un archivo refleja la naturaleza de su labor, la cual es puesta a disposición de los investigadores gracias a la función del archivero. La Iglesia Católica, en ese sentido, ha dado una valoración especial a este trabajo de memoria de Cristo y ha marcado un camino para esta singular profesión.

1 El discurso completo puede leerse en el portal de La Santa Sede. «Discorso di Paolo VI agli archivisti ecclesiastici», 26 de setiembre de 1963. < h t t p : / / w w w . v a t i c a n . va/holy_father/paul_vi/speeches/1963/documents/hf_pvi_spe_19630926_archivisti-ecclesiastici_it.html >. 


\section{BIBLIOGRAFÍA}

Aguilera Murguía, Ramón y Jorge Garibay Álvarez

2010 Teoría y técnica para para organizar los archivos de la Iglesia. México: Apoyo al Desarrollo de Archivos y Bibliotecas de México, A.C.

Gutiérrez, Laura y Javier Campos y Fernández

2012 La orden de San Agustín en el Archivo del Arzobispado de Lima: Lima: Instituto Escurialense de Investigaciones Históricas y Artísticas, San Lorenzo del Escorial

El Vaticano

1983 Código de Derecho Canónico. Disponible en <www.vatican.va/ archive/ESL0020/_INDEX.HTM>. 